\title{
Oficina temática do refrigerante: problematizando os conceitos de ácidos e a visão sobre a química
}

Amanda Pini Semensate

amandasemensate@hotmail.com

Universidade Estadual de Maringá (UEM) Maringá, Paraná, Brasil

Vanessa Carolina Volpato vanessavolpato13@gmail.com Universidade Estadual de Maringá (UEM) Maringá, Paraná, Brasil

Ana Paula Julião Mochizuki anap.mochizuki@gmail.com Universidade Estadual de Maringá (UEM), Maringá, Paraná, Brasil

\section{Murillo Sotti da Silva}

murillo@sotti.com.br

Universidade Estadual de Maringá (UEM), Maringá, Paraná, Brasil

Marcelo Pimentel da Silveira martzelops@gmail.com Universidade Estadual de Maringá (UEM), Maringá, Paraná, Brasil

\section{RESUMO}

O presente estudo teve como objetivo investigar as contribuições da aplicação de uma Oficina Temática (OT) pelo PIBID Química/UEM. A oficina teve como tema o refrigerante no processo de desmistificação de concepções sobre ácidos; o refrigerante na problematização da visão sobre a química; e o refrigerante na relação da química com o cotidiano. Assim, foi desenvolvido a OT com alunos recém-ingressos do curso de Química Licenciatura e Bacharelado da Universidade Estadual de Maringá (UEM), durante uma atividade de boasvindas aos calouros. Os dados foram analisados por meio da Análise de Conteúdo, possibilitando compreender que os alunos possuem visões distorcidas e descontextualizadas sobre ácidos e a química, podendo isso ser compreendido como reflexo da forma como a disciplina de química é ministrada durante as aulas. Todavia, podemos dizer que a OT gerou um conflito entre as ideias iniciais dos estudantes, o que oportunizou aos alunos construírem uma concepção mais contextualizada sobre o tema abordado.

PALAVRAS-CHAVE: Concepções. Tema Gerador. PIBID. Ensino de Química. 


\section{INTRODUÇÃO}

O PIBID Química/UEM realiza diversas atividades com o intuito de articular a Licenciatura em Química com a educação do Ensino Superior e Escola Pública, como campo de trabalho. $O$ projeto também tem proporcionado estudos teóricos que fundamentam os bolsistas na elaboração de materiais didáticos, sequências didáticas, Oficinas Temáticas (OT), atividades científico-culturais, entre outras atividades, que priorizem a construção do conhecimento e permitem aproximar o futuro docente da realidade das salas de aulas. Dentre essas atividades, são oferecidas OT, que têm como objetivo estabelecer relações entre os conhecimentos químicos e questões ambientais, econômicas e sociais, por meio de uma abordagem problematizadora.

A abordagem utilizada para a elaboração das OT no PIBID Química/UEM está fundamentada nos pressupostos discutidos por Marcondes et al. (2007) evidenciados no livro Oficinas Temáticas: Formação Continuada, no qual a oficina é organizada metodologicamente, pelos três momentos pedagógicos (3MP) e norteada por um tema gerador que articula experimentos e conceitos científicos. Essa perspectiva pode oportunizar ao aluno reinterpretar seus conhecimentos, por meio dos conceitos científicos trabalhados, adquirindo novos significados.

Para se compreender melhor a abordagem da OT, é importante apresentar uma breve discussão dos 3MP (DELIZOICOV; ANGOTTI; PERNAMBUCO, 2002), apresentados pedagogicamente como a problematização inicial, organização do conhecimento e aplicação do conhecimento. De acordo com os autores, a problematização inicial é o momento em que o aluno é instigado a expor suas ideias sobre um determinado assunto do seu cotidiano por meio de uma situação problema. Nesta etapa, o papel do professor é fazer um levantamento dos conhecimentos prévios dos alunos e criar situações em que o conhecimento que possuem seja insuficiente para tal explicação, assim, provocando uma insatisfação nesse aluno e, consequentemente, a necessidade da procura de novos conhecimentos. A organização do conhecimento apresenta o momento em que o professor utiliza algumas estratégias para que o aluno construa o conhecimento científico para explicar o problema inicial. E por último, a aplicação do conhecimento é uma nova situação a qual o aluno aplica o conhecimento científico, de forma que transcenda o problema inicial.

Todos esses momentos valorizam o diálogo entre aluno e professor e buscam romper com o ensino centrado na transmissão e recepção de conhecimentos, denominado "ensino tradicional". Nessa perspectiva, o aluno é protagonista do processo de aprendizagem e o papel do professor é mediar o conhecimento (MUECHEN; DELIZOICOV, 2010), assim, as atividades são fundamentadas em uma sequência lógica, que relacionam os três momentos pedagógicos, tendo como fio condutor os problemas inerentes a um tema gerador.

O tema gerador, em uma perspectiva freireana, discutida por Delizoicov (1983) exige algumas etapas do que o autor denomina como investigação temática. Por meio desta investigação, o tema emerge como um gerador de conflitos entre os indivíduos de um determinado contexto.

Nessa linha, concordamos com Silveira e Kiouranis (2017), quando discutem 
pertinente à sua realidade. Os mesmos autores também discutem que o ensino por temas não deve ser uma mera exemplificação de assuntos cotidianos, mas deve abordar os conceitos por meio da problematização, que não é somente a realização de perguntas, mas sim a reflexão sobre as questões e o problema em um determinado contexto, fazendo com que o aluno perceba a necessidade do saber científico para chegar às respostas e à compreensão da problemática central.

Para a abordagem temática no ensino da química, se faz necessária a contextualização dos conhecimentos, conteúdos e conceitos, no sentido de "problematizar o mundo dos alunos por meio do conhecimento científico, juntamente com saberes de outras áreas, de forma a permitir uma compreensão mais ampla da realidade na qual eles estão inseridos" (SILVEIRA; KIOURANIS, 2017, p. 69).

De acordo com Wartha e Faljoni-Alário (2005), que também dialogam sobre essa perspectiva de ensino, contextualizar é construir novos significados para o aluno, englobando valores que permitam o entendimento de questões sociais e culturais, que não sejam uma mera exemplificação, mas que conduza o aluno a compreender a importância do conhecimento científico no contexto do mundo que o cerca.

Nesse sentido, os temas são pontos de partida para se ensinar os conteúdos químicos de forma contextualizada, potencializando um maior desenvolvimento da compreensão de aspectos do mundo físico relacionados ao tema, instigando o aluno a criar seu ponto de vista, colocar suas ideias prévias em conflitos e por meio destas, construir novos conhecimentos que possam ser mobilizados no seu dia a dia, no sentido dos alunos tomarem decisões conscientes enquanto cidadãos, utilizando o conhecimento químico para olhar a realidade de forma mais crítica (MARCONDES et al., 2007).

Dessa forma, mesmo que o tema refrigerante, proposto para a OT, não tenha emergido de uma investigação temática, como discute Delizoicov (1983), ainda entendemos que este pode ser considerado um tema gerador, na medida que atende as características propostas por ser um assunto atual e polêmico, pois é consumido mundialmente pela maioria dos jovens, adultos e crianças e, além disso, todos possuem opiniões, críticas ou dúvidas a seu respeito, acerca dos malefícios e benefícios que a bebida pode causar, promovendo um conflito entre as concepções prévias dos indivíduos e o conhecimento científico.

Em virtude disso, esta temática possibilita ao aluno compreender conceitos químicos relacionados ao seu cotidiano e como eles podem influenciar em sua vida e promover o senso crítico, ou seja, as atividades desenvolvidas por meio de um tema gerador possibilitam que os alunos façam suas escolhas conscientes no dia a dia.

A problematização do tema refrigerante exige a compreensão de vários conceitos científicos inerentes à química, à biologia, entre outros, bem como de questões sociais e econômicas que estão diretamente relacionadas ao consumo pela população, possibilitando uma abordagem interdisciplinar. Nesta OT, optouse por discutir os conceitos sobre ácidos e as concepções alternativas que podem surgir, com um enfoque na compreensão da nocividade destes compostos para a saúde humana e noções sobre a química como algo ruim. 
Autores como Figueira et al. (2009) e Oliveira (2008), discutem que grande parte dos alunos relacionam o termo ácido a algo corrosivo e que queima, sendo maléfico à saúde humana, como também não estariam presentes no nosso cotidiano. Outra visão distorcida apresentada comumente pelos alunos é discutida por Rocha et al. (2005), no sentido de que os produtos naturais são isentos de química, enquanto os materiais com agrotóxicos ou industrializados, certamente fazem mal à saúde por contê-la, apresentando uma percepção pejorativa da mesma em nosso dia a dia e associando a palavra química, sempre a algo nocivo.

Tais concepções também são comentadas por Arroio (2006), frutos da falta de interesse dos alunos em química e, consequentemente, o surgimento de uma visão descontextualizada, referindo-se a mesma como a vilã do meio ambiente, caracterizando os produtos saudáveis pela ausência de química. Muitas dessas concepções negativas, irreais e destrutivas, surgem de informações veiculadas por propagandas, jornais, filmes, desenhos, ou até mesmo crenças populares, que influenciam crianças, jovens e adultos (ROCHA, et al., 2005).

Além disso, algumas dessas concepções a respeito da visão da química e de ácidos também surgem pelo fato de o ensino de química, na maioria das vezes, ser apresentada de forma distanciada do cotidiano e da vivência dos estudantes, potencializando o desenvolvimento de visões distorcidas sobre as mesmas. Outro exemplo seria a compreensão da química como a vilã e culpada pela poluição do ar, água e solo, deixando de lado o papel do ser humano nesse processo, desconsiderando o controle de fontes poluidoras, melhorias em indústrias e o tratamento correto de efluentes como atribuição à química (BRASIL, 2000).

Assim, o presente trabalho tem como objetivo investigar as concepções dos alunos recém-ingressos no curso de química, sobre ácidos e as visões sobre a química, pois espera-se que os alunos já tendo passado pela educação básica, deveriam ter uma noção mais científica sobre tais questões. Também buscamos compreender se a abordagem proposta foi capaz de possibilitar aos alunos desmistificar as ideias sobre os aspectos discutidos.

\section{PROCESSO DE ELABORAÇÃO DA OFICINA TEMÁTICA}

Pensando nas concepções que os alunos possuem sobre a química e mais especificamente sobre ácidos, discutidas anteriormente, a Oficina dos refrigerantes foi desenvolvida com o objetivo principal de desmistificar essas concepções, contextualizando-as por meio de um tema abrangente, o refrigerante. Nesse sentido, cabe apresentar tanto o processo de elaboração da OT, quanto sua estrutura e principais características.

A OT discutida neste trabalho se caracteriza como uma reelaboração de versões anteriores produzidas pelo PIBID Química/UEM. A primeira versão foi elaborada no ano de 2011 e trazia como problemática central a seguinte questão: "Refrigerantes, que características apresentam essa bebida que tanto fascina?" (CORTEZ et al., 2011, p. 7). O enfoque desta oficina estava centrado na investigação das concepções dos alunos acerca da composição do refrigerante, buscando problematizar tais ideias e desenvolver uma visão crítica sobre a bebida como algo saudável ou não. 
Os resultados apresentados em uma primeira investigação (CORTEZ et al., 2011), deixaram entrever que os alunos percebem que a bebida não se caracteriza com saudável ao consumo diário, contudo, grande parte dos investigados assume essa causa ao fato do refrigerante apresentar um caráter ácido, reforçando a ideia de ácido como algo ruim, conforme apresentado anteriormente como uma concepção recorrente dos alunos.

Nessa perspectiva, a fim de problematizar a concepção de que o refrigerante pode ser prejudicial por apresentar acidez, emergiu, no contexto do projeto, a necessidade de reelaboração desta OT, com o objetivo de trazer diferentes atividades capazes de permitir a compreensão de outros aspectos relacionados a essa bebida, na tentativa de desmistificar a ideia de que os materiais ácidos são nocivos à saúde do homem.

Como grande parte dos alunos que participaram da primeira versão desta OT relacionavam o termo ácido a algo corrosivo (CORTEZ et al., 2011), que queima, faz mal à saúde e não está presente em nosso cotidiano, entendeu-se a necessidade de incluir o suco natural de laranja nas atividades propostas para a segunda versão da OT, visto tratar-se de uma bebida que de forma geral, os alunos entendem como saudável, mas que também possui um caráter ácido.

Nessa segunda versão, elaborada no ano de 2014 (OLIVEIRA et al., 2014), priorizou-se a problematização da visão de ácidos que os participantes anteriores haviam apresentando, bem como de momentos que proporcionassem a introdução aos conceitos de ácidos e bases segundo a teoria de Arrhenius, conforme será apresentado na próxima seção.

Para isso, as atividades experimentais, que antes continham apenas uma análise do refrigerante, passaram a incorporar o suco de laranja, na tentativa de evidenciar que ambos apresentam caráter ácido, contudo o suco possui em sua composição, elementos necessários para manutenção da vida, portanto pode ser considerado, se não for consumido em excesso, saudável.

Ainda nesta segunda versão (OLIVEIRA et al., 2014), mesmo que não tenha sido feito uma investigação sistemática, como na primeira (CORTEZ, et al., 2011), percebeu-se que alguns assuntos abordados, como por exemplo, o fato do refrigerante causar osteoporose ou então o porquê o suco pode ser considerado saudável, não foram devidamente explorados. O resultado disso foi 0 desenvolvimento, em alguns casos, de uma visão simplista sobre esses aspectos, além de reforçar a concepção de que o suco é saudável "pois não contém química", consolidando a química como algo ruim.

Deste modo, pensando em toda essa discussão e nas evidências de que a OT tinha um potencial de explorar com mais profundidade as concepções alternativas que os alunos vinham apresentando, viu-se a necessidade de no ano de 2016, reelaborar essa OT a partir da análise das versões anteriores e dos resultados obtidos por meio das aplicações.

Realizada esta análise e pensando na importância de problematizar esses aspectos, para a terceira versão (2016) da OT, buscamos elaborar atividades capazes de gerar conflitos e proporcionar aos alunos a criação de significados aos novos conceitos propostos, por meio de experimentos e discussões. Nesse sentido, é importante ressaltar que algumas atividades foram mantidas das versões 
anteriores, pois apresentam em nossa concepção, um grande potencial para discussão dessa temática.

\section{OT DO REFRIGERANTE: ESTRUTURA E ATIVIDADES}

A organização da OT, como já discutido anteriormente, está centrada nos três momentos pedagógicos e a versão aplicada pode ser ilustrada pelo seguinte esquema:

Esquema 1: Estrutura da OT

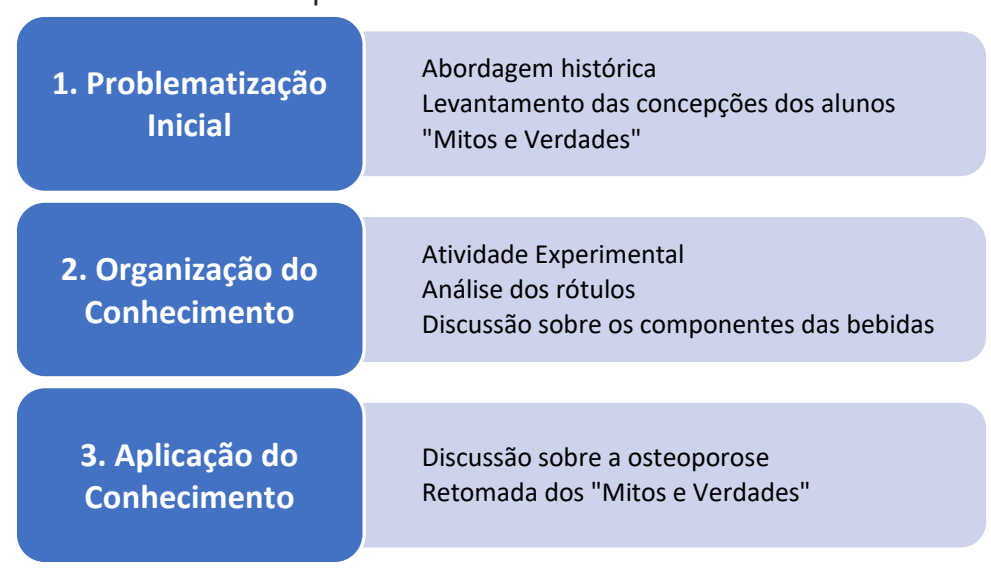

Fonte: Autoria Própria (2017).

\section{Problematização Inicial}

Para iniciar a discussão sobre o tema, optamos por utilizar uma abordagem histórica, enfatizando a origem do refrigerante, como sua criação e comercialização em farmácias, seu uso como medicamento e as marcas mais conhecidas mundialmente na atualidade, apresentando fotos e imagens para enriquecer a discussão.

Adiante, os alunos foram questionados oralmente, sobre a preferência entre suco e o refrigerante, para que assim, fosse possível perceber o que eles compreendiam sobre o Tema e também instigá-los a pensar em que aspectos eles levaram em conta para fazer tal escolha. O objetivo desta questão inicial foi provocar os participantes a se questionarem sobre quais os possíveis motivos para suas preferências, ou seja, o que eles levam em consideração ao preferirem suco ou refrigerante: o sabor?; a composição?; questões de saúde?; opções de dieta? Além disso, como essa questão faz referência a uma escolha pessoal e os alunos tendem a se manifestar de forma espontânea, também objetivou-se neste primeiro contato desenvolver um espaço dialógico, no qual todos devem possuir vez e voz para expor suas ideias. Este espaço se configurou como fundamental para um bom andamento da OT, à medida que as atividades foram pensadas com enfoque no aluno como protagonista de sua aprendizagem.

Em seguida, como problematização inicial, foi apresentado um conjunto de proposições, dispostas no Quadro 1, as quais os alunos assinalaram como "Mito ou Verdade", e justificá-las. Essas proposições foram elaboradas levando em consideração as concepções prévias sobre a química e o conceito de ácido que os 
alunos têm apresentado, tanto em estudos da literatura, discutidos anteriormente, quanto nas aplicações das versões anteriores a esta.

A escolha de utilizar as proposições como "Mitos e Verdades" para problematizar a temática refrigerante tem sido recorrente nesse PIBID. Isto está atrelado a resultados de outros trabalhos do próprio projeto (ROCHA et al., 2015), cuja abordagem se mostrou muito positiva no sentido de provocar os alunos a refletirem acerca das proposições e aguçar sua curiosidade em compreender se as afirmações tratam-se de mitos ou verdades.

Quadro 1 - Problematização inicial

\section{Mitos ou verdades}

1. O refrigerante causa uma deficiência de cálcio nos ossos (osteoporose), porque é ácido.

2. O refrigerante é prejudicial à saúde porque contém muita química.

3. O suco de laranja natural faz bem à saúde, por não conter química.

4. Tanto o suco natural de laranja quanto o refrigerante, apresentam valores energéticos elevados.

Fonte: Autoria própria (2017).

Após responderem, individualmente e por escrito aos "Mitos ou Verdades", os alunos foram questionados: "Existe alguma semelhança entre o suco e o refrigerante? Quais?". Essa questão buscou articular o primeiro e o segundo momento da OT e, ainda, possibilitou abranger melhor as discussões posteriores sobre as proposições, permitindo que os alunos começassem a pensar na composição do suco e do refrigerante, devido ao caráter ácido de ambos.

\section{Organização do Conhecimento}

As atividades que compõem o segundo momento pedagógico estão organizadas conforme apresenta o Quadro 2. 
Quadro 2. Atividades desenvolvidas na Organização do Conhecimento

\begin{tabular}{c|c} 
Atividade & \multicolumn{1}{c}{ Descrição } \\
\hline $\begin{array}{c}\text { Atividade Experimental - } \\
\text { básico e neutro dos materiais. }\end{array}$ & $\begin{array}{r}\text { A atividade consiste na investigação do caráter } \\
\text { dos materiais e, posteriormente, no agrupamento } \\
\text { destes seguindo critérios escolhidos pelos alunos. } \\
\text { Também são discutidos os conceitos de } \\
\text { indicadores e pH. }\end{array}$ \\
\hline Análise dos Rótulos & $\begin{array}{r}\text { Nesta atividade os alunos recebem rótulos do } \\
\text { suco natural de laranja e de diferentes marcas de } \\
\text { refrigerantes. O objetivo é que os alunos } \\
\text { comecem a perceber a composição dos dois } \\
\text { materiais, notando as diferenças e semelhanças e, } \\
\text { principalmente, que ambos possuem química. }\end{array}$ \\
\hline
\end{tabular}

Fonte: Autoria própria (2017).

$\mathrm{Na}$ atividade experimental, os alunos investigaram vários materiais como a água, água com gás, suco de laranja, refrigerante, solução de leite de Magnésia e solução de bicarbonato de sódio, identificando suas características ácidas ou básicas com o auxílio do indicador universal.

Os resultados experimentais foram anotados e discutidos coletivamente, relembrando as respostas da pergunta: "Existe alguma semelhança entre o suco e o refrigerante? Quais?", sempre fazendo relações aos "Mitos ou Verdades". O objetivo estava centrado na tentativa de estabelecer reflexões os conceitos químicos, para que na terceira etapa os alunos fossem capazes de responder a problemática proposta.

Ao término do experimento os alunos foram questionados novamente: "Se ambos possuem caráter ácido e o refrigerante causa osteoporose porque é ácido, então o suco de laranja também poderia causar osteoporose?". O objetivo desta indagação foi propor um diálogo e garantir a reflexão dos alunos sobre as proposições, visto que não é a acidez que os tornam prejudiciais ou não a saúde.

Vale ressaltar que para que se possa explorar ao máximo a atividade experimental, é proposto um questionário pós-experimento, como mostra o Quadro 3. 
Quadro 3. Questões Pós-Experimento

Questões Pós-Experimento

1. É possível separar os materiais analisados em grupos diferentes? Caso sua resposta seja afirmativa, qual(is) critério(s) você pode propor para esta separação?

2. A água ao interagir com o hidróxido de magnésio, $\mathrm{Mg}(\mathrm{OH})_{2}$, (principal componente do leite de magnésia) torna o meio com caráter básico, que é demonstrado pela mudança de cor da solução com o indicador universal. Dentre os materiais analisados, quais apresentam a mesma propriedade? Justifique. (Adaptado do livro do GEPEQ, 2009)

3. Alguns materiais ao interagirem com água tornam o meio com caráter ácido. Com base no experimento proposto e nos resultados tabelados, pode-se inferir que temos materiais com estas características? Quais? (Adaptado do livro do GEPEQ, 2009)

4. Com base no experimento realizado, vocês puderam observar alguma semelhança no comportamento do refrigerante e do suco de laranja. A que se deve esta semelhança? Como foi possível constatá-la?

Fonte: Autoria própria (2017).

As questões pós-experimento permitiram que os alunos analisassem e refletissem sobre os resultados experimentais de forma mais crítica. Além disso, as questões 2 e 3 trazem algumas informações que podem ser compreendidas como essenciais para a construção dos conceitos de ácidos e bases na perspectiva apresentada por Arrhenius. Isso se caracteriza como uma ótima oportunidade para que os professores de química responsáveis pelos alunos que participam dessa OT, possam retomar este conceito em sala de aula e discuti-lo de maneira mais aprofundada, visto que o tempo para o desenvolvimento desta OT é muito curto (duas a três horas).

A outra atividade desenvolvida neste momento pedagógico foi à análise de rótulos de vários refrigerantes e do suco natural de laranja. Nessa etapa, a análise proporciona a interpretação das informações contidas nos rótulos, correlacionando os componentes de cada produto com os aspectos nutricionais, suas principais diferenças, a necessidade do mesmo para o consumidor na hora da compra e principalmente, que o suco de laranja também possui química como os refrigerantes, diferindo apenas em quais são esses componentes químicos e, além disso, destacando as funcionalidades para o produto, a nocividade para a saúde e a importância para a manutenção do nosso organismo.

Para finalizar o segundo momento, questionou-se os alunos sobre: "Os refrigerantes causam osteoporose?". Como até este momento os alunos já realizaram diferentes atividades que evidenciam que o refrigerante e o suco apresentam caráter ácido, a questão acima torna-se pertinente no sentido de problematizar uma possível ideia prévia do aluno, de que os refrigerantes causam osteoporose pois são ácidos e corroem os ossos. O objetivo neste momento é fazer com que os alunos pensem a respeito e aproveita-se a questão para articular a organização do conhecimento com a aplicação do conhecimento.

\section{Aplicação do conhecimento}


$\mathrm{Na}$ aplicação dos conhecimentos, retomamos a atividade experimental e a análise dos rótulos, no sentido de fazer um fechamento sobre tudo que foi discutido ao longo da OT e também diagnosticar se os alunos apresentam alguma dúvida em relação às atividades ou às discussões feitas anteriormente. Se isso for percebido, buscamos explorar as dúvidas no coletivo, com objetivo de problematizá-las e elucidá-las.

Em seguida, apresentamos aos alunos a causa da osteoporose nos ossos, no qual, por meio de equações químicas, mostramos que ao ingerirmos em excesso os refrigerantes que possuem fosfato $\left(\mathrm{PO}_{4}{ }^{3-}{ }_{(\mathrm{aq})}\right)$ em sua composição, podemos aumentar nossas chances de desenvolver a osteoporose, uma vez que o íon cálcio $\left(\mathrm{Ca}^{2+}{ }_{(\mathrm{aq})}\right)$ presente na corrente sanguínea reage com o fosfato formando o fosfato de cálcio $\left(\mathrm{Ca}_{3}\left(\mathrm{PO}_{4}\right)_{2(\mathrm{~s})}\right)$. Essa discussão tem por objetivo desmistificar a visão dos estudantes que o ácido presente no refrigerante corrói os ossos, quando na verdade, ele "captura" os íons cálcios, impedindo a reposição celular nos ossos (MORAIS, BURGOS, 2007).

Por fim, é discutido sobre as características do refrigerante e do suco, sobre suas composições químicas e sobre a causa da osteoporose. Nesta etapa, entregou-se novamente os "Mitos e Verdades" e solicitou-se que os alunos, de forma individual, respondessem justificando suas respostas, independente se sua escolha entre "Mitos e Verdades" permanecesse a mesma do início da OT.

O objetivo dessa etapa foi perceber se as atividades desenvolvidas ao longo da OT permitiram aos alunos o desenvolvimento de uma visão mais contextualizada sobre a química e o conceito de ácido. Também buscamos avaliar se suas respostas apresentaram uma linguagem mais elaborada que se distancia do senso comum, mesmo se mantivessem a opinião inicial de mito ou verdade.

Nesse sentido, ao lançarmos um olhar para as concepções apresentadas pelos alunos, nos "Mitos e Verdades" ao início e ao término da OT, podemos perceber se a terceira versão desta atividade tem atingido os objetivos propostos: desmistificar a visão da química como algo ruim; investigar e discutir as possíveis concepções alternativas acerca do conceito de ácido. Dessa forma, buscamos responder a seguinte questão: A Oficina Temática do refrigerante tem contribuído para o rompimento de uma visão de senso comum sobre a química e os ácidos?

\section{PERCURSO METODOLÓGICO DA INVESTIGAÇÃO}

A presente pesquisa foi realizada com 16 alunos recém-ingressos ao primeiro ano do curso de Química Licenciatura e Bacharelado da Universidade Estadual de Maringá, por meio de uma OT aplicada durante uma atividade de boas-vindas aos calouros, no início do ano letivo de 2017. Utilizamos como instrumento de coleta de dados os "Mitos e Verdades" respondidos ao início e ao término da OT.

Os dados foram analisados qualitativamente por meio da Análise de Conteúdo de Bardin (1979), segundo os critérios da autora, esse método consiste na categorização das respostas a partir de uma leitura prévia, na seleção de unidades de registro, na quantificação dos dados e por fim na interpretação, de acordo com os pressupostos da investigação. Já a codificação dos dados, foi realizada permitindo ao pesquisador reconhecer a origem das falas de cada aluno, atribuindo letras ou números. No caso deste trabalho, foram atribuídas a letra $A$ 
de aluno, seguidos dos números de 1 a 16, mantendo assim a discrição dos participantes da OT.

\section{RESULTADOS E DISCUSSÕES}

Os resultados serão apresentados em quadros de acordo com cada proposição, nele são expostas as respostas aos "Mitos ou Verdades" de um mesmo aluno ao início e ao final da OT.

A primeira proposição tinha o objetivo de investigar as concepções dos alunos acerca das possíveis visões sobre o ácido como um material nocivo e corrosivo. Nesse sentido, buscamos perceber se os alunos apresentavam tais concepções utilizando um caso que é muito difundido no dito popular: "O refrigerante causa osteoporose", e as respostas à proposição 1 estão dispostas no quadro 4.

Quadro 4: Proposição 1 - “O refrigerante causa uma deficiência de cálcio nos ossos (osteoporose), porque é ácido".

\begin{tabular}{|c|c|}
\hline Mitos ou Verdades inicial & Mitos ou Verdades final \\
\hline $\begin{array}{c}\text { A5: "Verdade. Ácidos tem poder } \\
\text { corrosivo e por isso causa a deficiência } \\
\text { nos ossos." }\end{array}$ & $\begin{array}{l}\text { A5: "É um mito. Ele pode ajudar a causar } \\
\text { futuramente, mas não é o principal } \\
\text { causador." }\end{array}$ \\
\hline $\begin{array}{c}\text { A9: "Verdade, porque muito ácido faz } \\
\text { mal e corrói." }\end{array}$ & $\begin{array}{l}\text { A9: "Mito, o excesso de refrigerante pode } \\
\text { aumentar as chances de osteoporose." }\end{array}$ \\
\hline $\begin{array}{l}\text { A7: "Verdade, pois sua formulação tem } \\
\text { ácido corrosivo." }\end{array}$ & $\begin{array}{l}\text { A7: “Mito, o refrigerante "impede" que o } \\
\text { cálcio chegue aos ossos. O refrigerante em si } \\
\text { não causa osteoporose pode contribuir para } \\
\text { o desenvolvimento da doença." }\end{array}$ \\
\hline $\begin{array}{c}\text { A8: "Verdade. (Certo dia assisti uma } \\
\text { experiência, onde colocaram um osso } \\
\text { de galinha em um copo de coca, o osso } \\
\text { derreteu praticamente)." }\end{array}$ & $\begin{array}{l}\text { A8: "Mito. O acidulante presente no refri, } \\
\text { (principalmente nas de cola) consumido com } \\
\text { muito excesso pode contribuir para uma } \\
\text { deficiência nos ossos." }\end{array}$ \\
\hline $\begin{array}{l}\text { A2: “Mito, o nosso organismo tende a } \\
\text { manter-se em homeostase então } \\
\text { tentará neutralizar a acidez do sangue.” }\end{array}$ & $\begin{array}{l}\text { A2: “Mito. Os refrigerantes a base de cola } \\
\text { possuem ácido fosfórico, que se dissociam } \\
\text { em } \mathrm{H}^{+} \text {e } \mathrm{PO}_{4}{ }^{3-} \text {. O fosfato possui alta afinidade } \\
\text { com o } \mathrm{Ca}^{2+} \text { e precisa estar associado a ele } \\
\text { para ser metabolizado. Dessa forma o } \mathrm{Ca}^{2+} \\
\text { fica menos acessível para a fixação nos } \\
\text { ossos." }\end{array}$ \\
\hline
\end{tabular}

Fonte: Autoria própria (2017).

A princípio, na primeira proposição, $81 \%$ dos alunos participantes classificaram como verdade, apresentando justificativas como, o ácido contido nos refrigerantes em geral é corrosivo, podendo desgastar, corroer ou até mesmo retirar o cálcio contido nos ossos, ocasionando assim a osteoporose, como apresentado no quadro 4. As ideias iniciais dos alunos confirmam que os mesmos 
apresentam concepções alternativas sobre o conceito, de acordo com os resultados encontrados por Figueira et al., (2009, p.4), no qual os alunos relacionam "[...] o termo ácido a algo corrosivo, que queima e que é prejudicial à saúde".

Assim, embora os alunos apresentem tais concepções alternativas sobre ácidos, durante o segundo momento pedagógico, estes foram questionados sobre a existência de características semelhantes ao suco natural de laranja e ao refrigerante, investigando-as experimentalmente e, oportunizando a construção do conceito de que nem todo ácido é corrosivo e entrará em contato direto com os ossos, mas sim, que o consumo excessivo de refrigerantes à base de cola podem acirrar a deficiência de cálcio nos ossos, como apontam as justificativas dos "Mitos e Verdades" final, no quadro 4.

Além disso, Teixeira (2011), discute que os conflitos gerados das ideias iniciais dos estudantes são importantes para a superação da visão simplista e na construção tanto do conceito quanto da linguagem científica, evidente na fala A2 apresentada no quadro 4, que mesmo respondendo de forma correta inicialmente, apresentou uma mudança significativa em sua justificativa final.

A segunda proposição tinha como objetivo investigar se os alunos vinculavam a palavra "química" com algo ruim e que faz mal, isto é, no sentido pejorativo do termo. As respostas dessa proposição estão apresentadas no quadro 5, comparando as respostas dos mesmos alunos, no início e ao final da OT.

Quadro 5: Proposição 2 - “O refrigerante é prejudicial à saúde porque contém muita química".

\begin{tabular}{c|c} 
"Mitos ou Verdades" inicial & $\begin{array}{c}\text { "Mitos ou Verdades" final } \\
\text { toda industrial." }\end{array}$ \\
\hline $\begin{array}{c}\text { A11: "Verdade, a quantidade de açúcar e } \\
\text { conservantes é muito elevada." }\end{array}$ & $\begin{array}{c}\text { A11: "Mito, pois tudo tem química, porém a } \\
\text { composição do refri não é saudável. " } \\
\text { componentes são "vazios" de nutrientes } \\
\text { para nossa vida." }\end{array}$ \\
\hline $\begin{array}{c}\text { A13: "Verdade, ele é prejudicial por } \\
\text { conter muito açúcar." }\end{array}$ & $\begin{array}{c}\text { A13: "Mito, ele é prejudicial por ter as } \\
\text { substâncias em excesso." }\end{array}$ \\
\hline $\begin{array}{c}\text { A1: "Mito. O refrigerante contém muitas } \\
\text { substâncias, sendo algumas } \\
\text { não por ter muita química e sim por ter } \\
\text { muitas substâncias." }\end{array}$ & $\begin{array}{c}\text { A1: "Mito, ele não é prejudicial à saúde por } \\
\text { conter química, pois no suco de laranja } \\
\text { também contém. Porém ele é prejudicial } \\
\text { por conter componentes que não } \\
\text { necessitamos e que fazem mal a nossa } \\
\text { saúde" }\end{array}$ \\
\hline
\end{tabular}

Fonte: Autoria própria (2017).

Com relação à proposição $2,56 \%$ dos estudantes afirmaram positivamente que o refrigerante é prejudicial à saúde, expondo em suas justificativas, a compreensão de que a química está presente em produtos e alimentos industrializados, relacionando sempre ao fato de serem prejudiciais à saúde por contê-la. Assim concordamos com Ferreira (2007, p. 255), quando discute: 
[...] há muito tempo a imagem da Química vem sendo desgastada, devido às associações com desastres ecológicos e também pelo excesso de uso da palavra química como um verbete popular. Essa palavra tornou-se sinônimo de algo nocivo - por exemplo, quando alguém diz que este ou aquele produto tem "química", já está embutida a conotação de ruim.

Diante disso, esperava-se que os alunos recém-ingressos na Universidade, não apresentassem tais concepções, pois o ensino de química na educação básica deveria romper com tais visões simplistas, como indicam os PCN (BRASIL, 2000).

Já a proposição 3 , tinha o objetivo de desmitificar a ideia de tudo que contém química faz mal, pois sabe-se que no meio social o suco de laranja é visto como saudável, então como uma forma de provocar um conflito nas ideias dos alunos, se o refrigerante faz mal por conter química, necessariamente o suco de laranja faz bem por não contê-la, as respostas à esta proposição estão apresentadas no quadro 6.

Quadro 6: Proposição 3 - "O suco de laranja natural faz bem à saúde, por não conter química."

\begin{tabular}{|c|c|}
\hline "Mitos ou Verdades" inicial & "Mitos ou Verdades" final \\
\hline $\begin{array}{c}\text { A1: "Verdade. O suco é mais saudável, } \\
\text { porém a fruta pode conter excesso em } \\
\text { agrotóxico que fazem muito mal a } \\
\text { saúde." }\end{array}$ & $\begin{array}{l}\text { A1 “Mito, assim como o refrigerante o suco } \\
\text { de laranja natural também contém química e } \\
\text { mesmo assim é saudável." }\end{array}$ \\
\hline $\begin{array}{c}\text { A5: "Verdade. Pois não contém tantas } \\
\text { reações químicas quanto ao } \\
\text { refrigerante." }\end{array}$ & $\begin{array}{c}\text { A5: "Mito, ele contém química, mas faz bem } \\
\text { à saúde, pois contém vários nutrientes } \\
\text { essenciais." }\end{array}$ \\
\hline $\begin{array}{l}\text { A13: "Verdade, pois é extraído da polpa } \\
\text { da fruta." }\end{array}$ & $\begin{array}{l}\text { A13: "Mito, pois o suco mesmo sendo natural } \\
\text { contém química, em pequenas quantidades, } \\
\text { como vitamina C, fibra entre outros." }\end{array}$ \\
\hline $\begin{array}{c}\text { A16: "Verdade. Se é natural parece ser } \\
\text { bom, como se tivesse tomando a } \\
\text { própria fruta." }\end{array}$ & $\begin{array}{l}\text { A16: “Mito. Tudo tem química, porém sua } \\
\text { composição faz bem para a saúde." }\end{array}$ \\
\hline $\begin{array}{c}\text { A2: “Mito, a química não está apenas } \\
\text { nos industrializados, pois está presente } \\
\text { nas moléculas, na interação entre elas, } \\
\text { etc." }\end{array}$ & $\begin{array}{l}\text { A2: “Mito. O suco de laranja possui química } \\
\text { semelhante aos refrigerantes, como os } \\
\text { carboidratos. Porém, possuem vitamina C, } \\
\text { ferro, fósforo, proteínas, fibras, entre outras } \\
\text { químicas que são essenciais ao consumo } \\
\text { humano.” }\end{array}$ \\
\hline
\end{tabular}

Fonte: Autoria própria (2017).

Esta proposição, foi classificada como verdadeira por $44 \%$ dos alunos, pautada na justificativa que a química está presente em produtos industrializados e até mesmo agrotóxicos, apontando que a fruta é saudável por não conter química, como apresentada no quadro 6 . Tais concepções alternativas também puderam ser constatadas por Rocha et al., (2005), que afirma a visão de alguns alunos de que o natural não possui química, evidenciando uma percepção da mesma como 
a vilã, como discute também os PCNs (BRASIL, 2000), pois para os alunos, o que faz bem e é saudável não pode conter química.

A fim de desmistificar essa compreensão, foi possível, no momento de organização dos conhecimentos da OT, explicar que os componentes químicos presentes no suco são todos importantes para a manutenção da vida e o refrigerante contém compostos químicos que podem ser prejudiciais em grandes quantidades, mediante a análise dos rótulos dessas bebidas, para que os alunos percebessem essas principais diferenças nutricionais e de composição. Isso possibilitou aos alunos assimilar que a química não está presente somente em coisas que fazem mal, tanto à saúde quanto ao meio ambiente, mas também em alimentos e em nutrientes necessários para a manutenção do nosso organismo.

Por fim, o quadro 7 apresenta as respostas dos alunos à proposição 4, cujo objetivo era de desmistificar a ideia do que é natural é tão bom à saúde, que não pode ser nem calórico, o que pode ser contrariado pelos altos valores energéticos do suco de laranja e também do refrigerante.

Quadro 7: Proposição 4 - "Tanto o suco natural de laranja quanto o refrigerante, apresentam valores energéticos elevados".

\begin{tabular}{|c|c|}
\hline "Mitos ou Verdades" inicial & "Mitos ou Verdades" final \\
\hline $\begin{array}{l}\text { A1: "Verdade. Contém o valor } \\
\text { energético aproximado, a laranja em } \\
\text { bastante quantidade é muito calórica." }\end{array}$ & $\begin{array}{l}\text { A1: "Verdade, possuem os valores } \\
\text { energéticos elevados bem próximos, porém } \\
\text { o suco de laranja contém mais substâncias } \\
\text { que necessitamos e menos prejudicial." }\end{array}$ \\
\hline $\begin{array}{c}\text { A2: "Verdade, pois ambos são ricos em } \\
\text { açúcar." }\end{array}$ & $\begin{array}{c}\text { A2: "Verdade. Ambos possuem quantidades } \\
\text { semelhantes de carboidratos, porém o suco } \\
\text { de laranja possui outros nutrientes, } \\
\text { enquanto que o refrigerante é apenas } \\
\text { açúcar." }\end{array}$ \\
\hline $\begin{array}{l}\text { A4: "Mito, pois o suco é natural da fruta } \\
\text { e o refrigerante contém muito açúcar o } \\
\text { que faz com que seus valores } \\
\text { energéticos se elevem." }\end{array}$ & $\begin{array}{l}\text { A4: "Sim, o valor energético é parecido, } \\
\text { porém os benefícios do suco são maiores } \\
\text { em comparação ao refrigerante." }\end{array}$ \\
\hline $\begin{array}{c}\text { A7: "Mito, o refrigerante pois contém } \\
\text { mais açúcar." }\end{array}$ & $\begin{array}{l}\text { A7: Sim, porém o suco de laranja possui } \\
\text { valores energéticos e açúcares saudáveis." }\end{array}$ \\
\hline
\end{tabular}

Fonte: Autoria própria (2017).

Analisando as respostas, $32 \%$ dos alunos disseram ser um mito, apresentando justificativas com erros conceituais em relação à composição, como por exemplo, ao indicar a não existência de açúcar na fruta por ser natural, ou então respostas simplistas, afirmando apenas que o refrigerante tem mais açúcares como A7. No entanto, $68 \%$ dos alunos afirmaram ser uma verdade os altos valores energéticos, tanto do suco de laranja, quanto do refrigerante, como perceptível nas falas de A1 e A2, apresentadas no quadro 7. Contudo, após as discussões feitas durante a aplicação do conhecimento, os estudantes apresentaram uma modificação 
significativa em suas justificativas, utilizando-se de uma explicação mais científica para o fato.

Em virtude disso, oportunizou-se aos alunos, com o intermédio da análise dos rótulos, compreender e explicar, com uma linguagem científica, que mesmo o refrigerante e o suco de laranja apresentando valores energéticos altos, os benefícios dos componentes existentes no suco são necessários para nosso organismo, ao contrário do refrigerante.

Dessa forma, ressalta-se, a apropriação da linguagem científica, por meio do conjunto de ações de habilidades como, saber escrever, ler e explicar fenômenos e argumenta-los (OLIVEIRA; MUNFORD, 2014). Esses aspectos foram proporcionados aos alunos durante a OT, e evidentes em suas justificativas aos "Mitos ou Verdades" final, da proposição 4, pois os alunos passaram a fundamentar suas respostas, apropriando-se dos conceitos científicos.

Os resultados revelam que no decorrer da OT, as discussões propiciaram aos alunos a desmistificação de visões simplistas e errôneas, por meio do diálogo entre professor e aluno, aluno e aluno. Segundo Marcondes (2008) esses momentos de diálogo são importantes para a construção do conhecimento científico, permitindo que o aluno seja protagonista neste processo, visto que a partir do momento que ele tem um problema para resolver e seu conhecimento prévio é contestado ele passa a criar significados no que está aprendendo.

Portanto, podemos inferir que a OT possibilitou que os alunos (re)significassem suas concepções referentes ao tema nos diferentes momentos da OT. Além disso, também pode ser evidenciado, na maioria respostas dos alunos, que esta abordagem fundamentada na problematização, na contextualização e na experimentação, permitiu o diálogo aluno-professor e aluno-aluno favorecendo o desenvolvimento de uma visão mais crítica sobre a temática refrigerante e sobre a concepção de ácido, como demonstrado na fala dos alunos.

\section{CONSIDERAÇÕES FINAIS}

Embora os alunos investigados nessa pesquisa já tenham concluído o ensino básico e estejam cursando Química no Ensino Superior, um número significativo de alunos trouxeram consigo concepções distorcidas sobre a química, por exemplo, sobre ela estar presente em tudo que faz mal e relacionando o termo ácido a algo corrosivo. Isso nos leva a refletir que a disciplina de química, da forma que vem sendo ensinada no Ensino Médio, pode reforçar tais concepções.

No entanto, acreditamos que o ensino pautado em atividades que priorizem o diálogo aluno-professor, no qual o aluno tem papel ativo e é protagonista na construção do seu conhecimento e o professor atua como mediador neste processo, proporcionando momentos de reflexão que favorece a elaboração de novos significados para os conceitos químicos.

Além disso, entendemos que a Oficina Temática do Refrigerante, na medida que foi planejada e desenvolvida seguindo os pressupostos teóricos já apresentados, oportunizou aos alunos o desenvolvimento de uma visão mais contextualizada acerca de ácidos e da química, assim como proporcionou aos bolsistas do projeto PIBID Química/UEM pensarem em atividades que vão além da discussão conceitual, no sentido de problematizar aspectos sociais como, por 
exemplo, as propagandas que vinculam os refrigerantes com a algo que traz felicidade, sem expor os malefícios do consumo excessivo dessa bebida. Concluímos que a OT tem o potencial de possibilitar que os alunos tenham uma visão mais crítica e possam refletir sobre suas escolhas acerca do que consomem, considerando diferentes aspectos que antes não eram levados em conta. 


\title{
Thematic Workshop of Soda: problematizing the concepts of acids and the vision about Chemistry
}

\begin{abstract}
The current study had the objective of investigating the contributions of the Thematic Workshop (TW) by the PIBID of Chemistry/UEM, about sodas, in the process of demystification of conceptions about acids; in the problematizing vision about the Chemistry; and, in the relation of chemistry with daily life. Therefore, a TW has been developed with Chemistry major freshmen from the State University of Maringa, during the event of reception to the new students. The data has been analyzed through the method of Content Analysis, allowing to comprehend that the students have distorted and decontextualized visionsabout acids and Chemistry, making possible to assume it as a reflex of the way how the Chemistry subject is taught during the classes. However, it is possible to affirm that the TW generated a conflict between the students' initial ideas, creating the opportunity for the students to develop a more contextualized conception about the theme discussed.
\end{abstract}

KEYWORDS: Conceptions, Generator Theme, PIBID, Chemistry teaching. 


\section{AGRADECIMENTOS}

Agradecemos aos professores e bolsistas que fazem parte do projeto PIBID, pelos momentos de discussão e estudos teóricos para a elaboração da OT. E também a CAPES pelo apoio financeiro.

\section{REFERÊNCIAS}

ARROIO, A. O show da Química: motivando o interesse científico. Química Nova na Escola, v. 29, n. 1, 2006. Disponível em:

<http://quimicanova.sbq.org.br/imagebank/pdf/Vol29No1_173_30-

ED04399.pdf> Acesso em: 06 mai. 2017.

BARDIN, L. Análise de Conteúdo. Lisboa: Edições 70, 1979.

BRASIL. Parâmetros Curriculares Nacionais (PCNs): Parte III - Ciências da Natureza, Matemática e suas Tecnologias. Brasília: MEC / SEF, 2000.

CORTEZ, J. M.; KIOURANIS, N. M. M.; De SÁ, M. B. Z.; RODRIGUES, M. A. Contextualizando os conhecimentos químicos com a temática refrigerantes. In: V Encontro Regional Sul de Ensino de Biologia e IV Simpósio Latino Americano e Caribenho de Educação em Ciências do International Council of Associations for Science Education, 2011. Disponível em:

<http://www.uel.br/ccb/biologiageral/eventos/erebio/painel/T109.pdf> Acesso em: 14 mai. 2017.

DELIZOICOV, D. Ensino de física e a concepção freireana da educação. Revista Brasileira de Ensino de Física, v. 5, n. 2, p. 85 - 98, 1983. Disponível em: <http://www.sbfisica.org.br/rbef/pdf/vol05a19.pdf> Acesso em: 15 mai. 2017.

DELIZOICOV, D.; ANGOTTI, J. A.; PERNAMBUCO, M. M. Ensino de Ciências: Fundamentos e métodos. São Paulo: Cortez, 2002.

FERREIRA, V. F. A Química é sempre boa. Química nova na Escola, v. 30, n. 2, 255, 2007. Disponível em:

<http://quimicanova.sbq.org.br/imagebank/pdf/Vol30No2_255_00b-editorial302.pdf> Acesso em: 05 mai. 2017.

FIGUEIRA, M. C. A.; OLIVEIRA, A. M.; ROCHA, J. B. T. Concepções alternativas de estudantes do Ensino Médio: ácidos e bases. In: VII Encontro Nacional de Pesquisa em Educação em Ciências, 2009, Florianópolis-SC. Florianópolis-SC, 2015. Disponível em:

<http://posgrad.fae.ufmg.br/posgrad/viienpec/pdfs/366.pdf> Acesso em: 01 mai. 2017. 
GEPEQ - Grupo de Pesquisa em Educação de Química. Atividades Experimentais de Química no Ensino Médio: reflexões e propostas. São Paulo: Editora Universidade De São Paulo, 2009.

MARCONDES, M.E.R. Proposições metodológicas para o ensino de química: oficinas temáticas para a aprendizagem da ciência e o desenvolvimento da cidadania. Revista em extensão, v. 7, 2008.

MARCONDES, R. E. M. et al. Oficinas temáticas no ensino público: formação continuada de professores / Secretaria da Educação, Coordenadoria de Estudos e Normas Pedagógicas; - São Paulo: FDE, 2007. 108 p. Disponível em:<http://media.wix.com/ugd/4eb63d_31e03c36b6ea45738d6639d909d6b04f. pdf> Acesso em: 29 abr. 2017.

MUECHEN, C.; DELIZOICOV, D. Os três momentos pedagógicos: um olhar histórico-epistemológico. In: XII Encontro de Pesquisa em Ensino de Física, 2010, Águas de Lindóia-SP. Águas de Lindóia-SP, 2010.

MORAIS, G. Q.; BURGOS, M. G. P. A. Impacto dos nutrientes na saúde óssea: novas tendências. Revista Brasileira de Ortopedia, v. 42, n. 7, 2007, p. 189-194. Disponível em: $<$ http://www.scielo.br/pdf/rbort/v42n7/v42n7a02.pdf $>$. Acesso em: 29 Jun. 2017.

OLIVEIRA, A. M. de. Concepções alternativas de estudantes do Ensino Médio sobre ácidos e bases: Um estudo de caso. 2008. 71 p. Dissertação (Mestrado) Educação em Ciências: Química da vida e saúde, Universidade Federal do Rio Grande do Sul, Porto Alegre, 2008. Disponível em: <http://www.lume.ufrgs.br/bitstream/handle/10183/13870/000656392.pdf?seq uence $=1>$ Acesso em: 29 abr. 2017.

OLIVEIRA, S. G. T.; MUNFORD, D. Apropriação do discurso científico: uma análise do uso da linguagem científica em atividades de ensino de ciências com alunos da educação de jovens e adultos (EJA). Revista SBEnBio - Associação Brasileira de Ensino de Biologia, n. 7, Outubro, 2014. In: V Enebio e II Erebio Regional. Disponível em: <http://www.sbenbio.org.br/wordpress/wpcontent/uploads/2014/11/R0237-1.pdf> Acesso em: 29 abr. 2017.

OLIVEIRA, D. B.; OLIVEIRA, F. R.; ROCHA, L. S.; KIOURANIS, N. M. M.; SILVEIRA, M. $P$. Análise de uma oficina temática sobre o Refrigerante no contexto da formação inicial no PIBID Química/UEM. XVII Encontro Nacional de Ensino de Química (XVII ENEQ), Ouro Preto-MG, 2014. 
ensino de Química. In: IV Congresso Paranaense de Educação em Química, 2015, Curitiba-PR. Curitiba-PR, 2015.

ROCHA, Z. M.; MILARÉ, T.; SILVA, C. S.; MARQUES, R. N.; OLIVEIRA, L. A. A.; OLIVEIRA, O. M. M. F. de. A Química no universo dos alunos do Ensino Médio. In: V Encontro Nacional de Pesquisa em Educação em Ciências, 2005, Bauru-SP. Atas do $5^{\circ}$ Encontro Nacional de Pesquisa em Educação em Ciências. Disponível em: <http://www.nutes.ufr.br/abrapec/venpec/conteudo/artigos/1/pdf/p259.pdf> Acesso em: 02 mai. 2017.

SILVEIRA, M. P.; KIOURANIS, N. M. M. Combustíveis: uma abordagem problematizadora para o ensino de química. Química nova na Escola. - São Paulo-SP, BR. v. 39, n. 1, p. 68-74, fevereiro 2017. Disponível em: <http://qnesc.sbq.org.br/online/qnesc39_1/11-RSA-55-15.pdf> Acesso em: 05 mai. 2017.

TEIXEIRA, A. M. M. B. Concepções alternativas em ciência: Um instrumento de diagnóstico. 2011. 133p. Dissertação (Mestrado) - Curso de Biologia, Departamento de Ciências Sociais e Aplicadas, Faculdade de Ciências e Tecnologia da Universidade Nova de Lisboa, Lisboa, 2011. Disponível em: <https://run.unl.pt/bitstream/10362/7816/1/Teixeira_2011.pdf> Acesso em: 01 mai. 2017.

WARTHA, E.J., FALJONI-ALÁRIO, A. A contextualização no ensino de química através do livro didático. Química Nova na Escola, n. 22, p. 42 - 47, novembro, 2005. Disponível em: <http://qnesc.sbq.org.br/online/qnesc22/a09.pdf> Acesso em: 14 mai. 2017.

Recebido:30jul. 2017

Aprovado:20dez. 2017

DOI: $10.3895 /$ actio.v2n3.6856

Como citar:

SEMENSATE, A. P.; VOLPATO, V. C.; MOCHIZUKI, A. P. J.; SILVA, M. S.; SILVEIRA, M. P. Oficina temática do refrigerante: problematizando os conceitos de ácidos e a visão sobre a química. ACTIO, Curitiba, v. 2, n.

3, p. 229-248, out./dez. 2017. Disponível em: <https://periodicos.utfpr.edu.br/actio>. Acesso em: XXX Correspondência:

Amanda Pini Semensate

Avenida Herval, n. 1340, Zona 7, Maringá, Paraná, Brasil.

Direito autoral: Este artigo está licenciado sob os termos da Licença Creative Commons-Atribuição 4.0 Internacional. 